\title{
Innovative Application of Regional Symbols in Environmental Design of Urban Cultural and Creative Park
}

\author{
Xiaocong $\mathrm{Hu}$ \\ School of Design Arts and Fashion Engineering \\ Xiamen University of Technology \\ Xiamen, Fujian, China 361024
}

\begin{abstract}
In view of the current problems of image convergence in the construction of many urban cultural and Creative Park, put forward with real appeal force of Regional Symbols in the application of innovation in the design environment will help to preserve the memory of the city, shaping the profound cultural connotation of urban cultural and creative park image. Regional symbol is the embodiment of regional culture, and it has important significance of cultural transmission and inheritance, the connotation and construction process of regional symbols are analyzed in detail based on semiotics theory, put forward the application method of the regional symbol innovation, such as simplification of borrowing, deconstruction and reconstruction, etc, to provide innovative ideas for the regional distinctive urban cultural and Creative Park.
\end{abstract}

Keywords-cultural creative park; environmental design; regional symbol

\section{INTRODUCTION}

In recent years, with the upgrade of old industry and boom of cultural creative industry, many cities make use of idle industrial factory buildings to construct Cultural and Creative Park with cultural creative industry as the core. It plays a significant role in inheriting historic culture, activating idle assets, creating city image, promoting transformation and upgrading of industry, fostering atmosphere of innovation environment as well as advocating lifestyle and social custom. According to statistics, by 2015, there are more than 2,000 of cultural and creative industrial parks in our country, up to 500 of various cultural and creative industry projects, including 336 national cultural industry demonstration bases and ten cultural industry demonstration zones of national level in all over the country. However, the construction of Cultural and Creative Park that develops so rapid faces the embarrassment that "all parks are the same". Because the industrial development model of the park is basically similar to operating model, the thinking on the level of environmental design culture lacks in-depth and careful deliberation or mechanically applies a variety of cultural symbols, then the visual environment represented is largely identical but with minor

Fund program: Education and Scientific Research Project of Young Teachers "Research on Innovative Application of Regional Symbol in Environment of Urban Cultural and Creative Park" in Fujian Province in 2015 ( JAS150427)

「CLC] J525

「Document codel A

「Article number differences. Therefore, in order to better build attraction and competitive advantages of Cultural and Creative Park and enrich cultural connotation of environmental construction of Cultural and Creative Park, it shall attach importance to combining regional culture with unique characteristics with modern creative culture, abstracting and compacting regional symbols through excavation, arrangement and redesign and applying to environmental design of Cultural and Creative Park with skillful innovation application. It helps to reserve memories of the city, add sense of identity of people and promote integration of different cultures. Meanwhile, it also provides colorful creative environment materials in Cultural and Creative Park and shapes new regional fashion style.

\section{CONNOTATION AND CONSTRUCTION OF REGIONAL SYMBOL}

The so-called regional symbol is the embodiment formed by using semiotics theory to research connotation of regional culture. It involves every aspect of achievements of civilization and has characteristics of specific regional directionality and cultural consensus. In order to compact valuable regional symbols, it is essential to comprehensively understand connotation and framework of regional culture and then sort out the most representative connotation of regional culture. Firstly, regional culture is the cultural form with regional characteristics and attributes [1] and reflects behavior pattern and thinking model of particular groups within certain special scale; [2] Secondly, regional culture can be divided into tangible culture and intangible culture. The former is often presented by specific material objects, such as relics of historic buildings, natural environment, and means of production and local materials, which are easy to form direct cognition. The latter refers to relatively abstract and vague cultural forms such as academic thoughts, customs, judgments and festivals, folk arts and historical context, which are difficult for us to grasp exactly. The regions that regional culture belongs to are relative. For example, the scope of regional culture that takes a certain Cultural and Creative Park as the base point shall include urban region at macro level and community and site area that the Cultural and Creative Park is located in at micro level. The embodiment of its cultural value conforms to design positioning and strategy of the Cultural and Creative Park. 
Saussure, a linguist from Switzerland, defines symbol as the entirety formed by signifier and signified. "Signifier" refers to external form presented by symbols. "Signified" refers to internal meaning carried by symbols. The behavior and process of combination of signifier and signified is called as signification. The result of signification is symbol. [3] The construction of regional symbol is to use reasonable design methods to signify connotation of regional culture according to specific rules to form all kinds of perceptible design symbols. Firstly, designers divide symbols in conception into "signifier" and "signified" according to experience. "Signifier" refers to various components in environmental space, including elements such as spatial form, artistic modeling, pattern, color and material, even incorporeal elements in modern design such as sound, light and electricity; "Signified" refers to cultural connotation such as meaning, concept, structure and emotion represented by these elements. Secondly, extract cultural connotation with clear symbolic meaning from wide range of regional culture, refer to cognitive experience of audiences, connect meanings of "signifier" and "signified" and construct design symbols that represent its meaning. Thirdly, endow symbols with character of times, use rules of modern design forms to reconstruct symbols, which refer to reconstruction of symbols as well as relationship between symbols and environment, in order to reinforce representative characteristics of regional symbols.

\section{INNOVATIVE APPLICATION METHODS OF REGIONAL SYMBOLS}

Rudolf Arnheim says in Art and Visual Perception, "visual image is never mechanical copy of perceptual materials, but a kind of creative grasp of reality". Regional symbols under context also cannot immerse in images in the past. Traditional forms are always too complicated. The expression of color and materials is very limited. These are difficult to integrate with landscape of Cultural and Creative Park that advocates the expression of sense of design. Inappropriate application will increase the cost of design and cause ambiguity. Therefore, in order to achieve real innovative application, it is necessary to grasp connotation and essence of it and use methods such as simplification and borrowing, deconstruction and recombination to creatively combine with requirements of modern society, use new forms, new technology and new materials by keeping pace with the times, so that we can construct refreshing regional landscape environment.

\section{A. Simplification and Borrowing}

Simplification and borrowing is to directly compact traditional patterns, local decoration technology and materials and interpret natural quality and traditional connotation of environment after signifying. This is the most direct application method of regional symbol. The advantage is that it furthest reserves characteristics of regional symbols and has good identification in practical application. Regional symbols required by modern design often play the role of making the finishing point. With the help of simplification and borrowing, summarize and reserve the core part on signifier level, such as structural relationship and proportion, and then digitize, regularize and geometrize its forms, embody through some modern design methods, skills or materials and then produce new environmental semantics. As shown in "Fig. 1", Museum of Suzhou designed by Ieoh Ming Pei, a famous architect, implements the design philosophy of "Creativity with Chinese style, Suzhou Style with Creativity". On design, he simplifies design language of traditional Suzhou Gardens, makes efforts to explore modern expression of traditional meaning. The architecture coordinates with the surrounding traditional garden integrally, replaces traditional architecture symbols with modern materials and creatively solves the extension of traditional symbol semantics in new period.

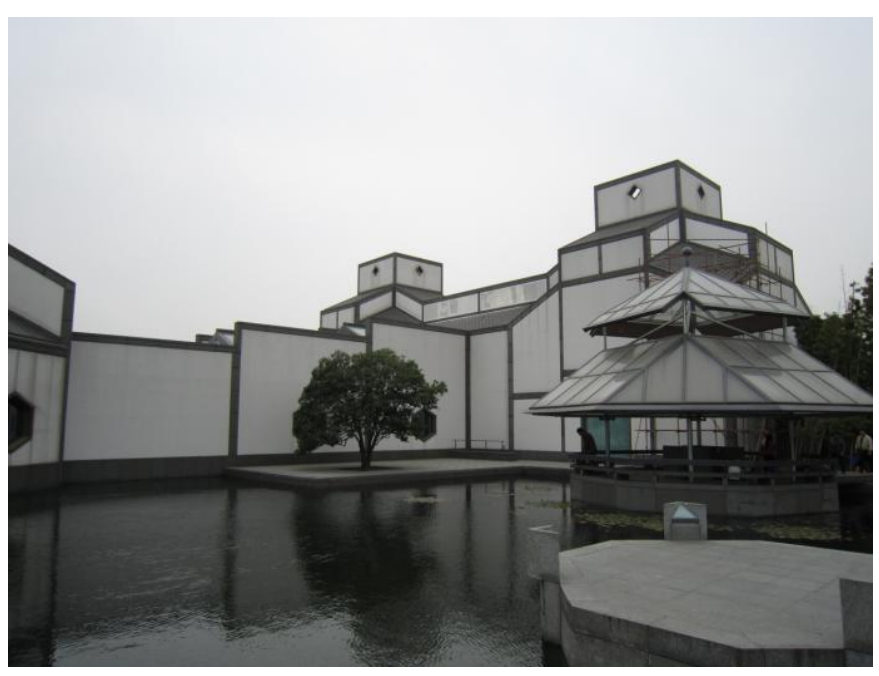

Fig. 1. Museum of Suzhou

\section{B. Deconstruction and Recombination}

The value of design lies in innovation. If designed objects get rid of the stale and bring forth the fresh, they will effectively attract people's attention. Innovation cannot break away from old things, or it will be easy to separate from reality. Therefore, adopting the method of deconstruction and recombination to realize innovation of regional symbol can produce new semantics and expressive value. The so-called deconstruction and recombination of regional symbol refers to scatter different types of symbols and separate it from the original context of symbol and recombine new symbol types and semantics. This method often carries out design of structure reengineering between application of single symbol and a variety of elements, or transfers regional symbols to new design objects, to create refreshing forms of regional symbols. Besides, deconstruct connotation of symbols on signified level, use new forms to deduce the original connotation and extend diversified semantics. As shown in "Fig. 2", the Signage System Design of Shanghai Xintiandi, redesign and recombine elements of tile in traditional architecture, use new constitution form to extend its functional significance and show characteristics of regional symbols in realizing identification functions. 


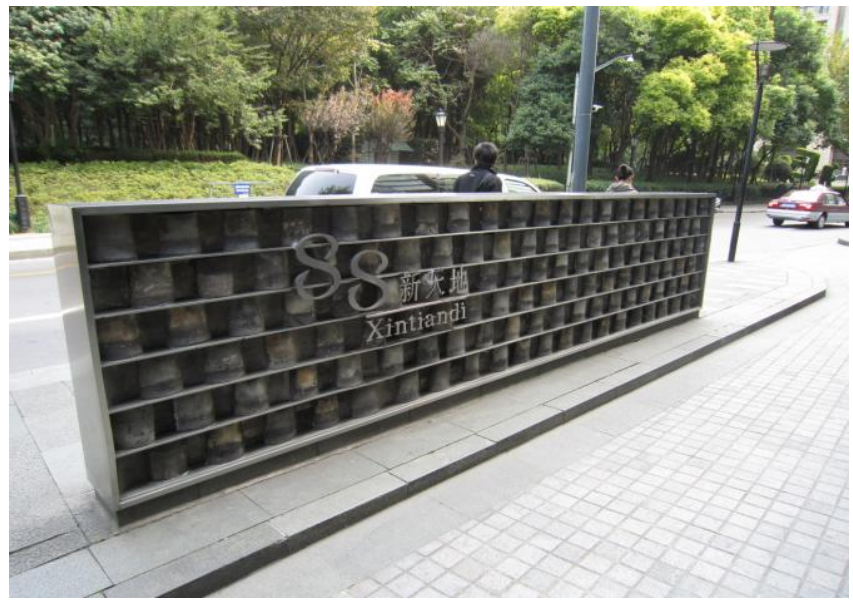

Fig. 2. Signage system design of Shanghai Xintiandi

\section{INNOVATIVE APPLICATION STRATEGIES OF REGIONAL SYMBOL IN ENVIRONMENTAL DESIGN OF CULTURAL AND CREATIVE PARK}

The environment of Cultural and Creative Park is formed by all kinds of design elements, such as street paving, building elevation, plant greening, store image, street furniture and public facilities. Regional symbols can embody different connotations in these design elements. But it shall base on requirements of design tasks and proper innovative application strategies to meet people's deep psychological needs for feeling regional culture and create a kind of new visual pattern that people yearn for as well as stimulate people's identification for environment of Cultural and Creative Park.

\section{A. Build Proper Symbolic Forms}

All semantics in environment need to be conveyed to audiences through visible symbolic forms. Proper symbolic forms are also important media for audiences to understand context semantics. For environment of Cultural and Creative Park, proper symbolic forms include two aspects of meanings. Firstly, in terms of source of regional symbols, designers shall explore rules that can be cognized and formed by the most general user groups, thus the visual communication can realized just as expected. [4] On one hand, analyze symbols of the site in macro urban or regional culture that the park is located in, meanwhile, pay attention to unique spiritual symbols in lifestyle of community. For example, turn urban spirit or lifestyle of community into the ways of public art to integrate in the park environment and play the role of highlighting regional characteristics; on the other hand, extract regional symbols from micro heritage of old industrial building in the park or industrial features in the park, make glorious history in the park reappear through combination with landscape elements. As shown in "Fig. 3", coat striking colors on used equipment left in the original industry, use visual language of modern art to transform regional symbols to form environment symbols with visual impact; Secondly, for the forms of symbols, it is necessary to build different symbolic modeling languages according to original spirit, functional characteristics and affective meaning of environment in Cultural and Creative Park. These symbols shall be concise and easy to be identified and conform to artistic characteristics of space in Cultural and Creative Park; as shown in "Fig. 4", in the transformation of historical blocks in Beijing Dashilan, skillfully change the traditional symbol of drum-shaped bearing stone into dustbin. The appearance of this kind of regional symbols is easy to be identified by the audiences. Besides, it is not enough to pay attention to the formal beauty of single symbol. It shall also moderately design combining with specific position of application according to mutual harmony of symbols and environment, forms, size scale and proportion of symbols.

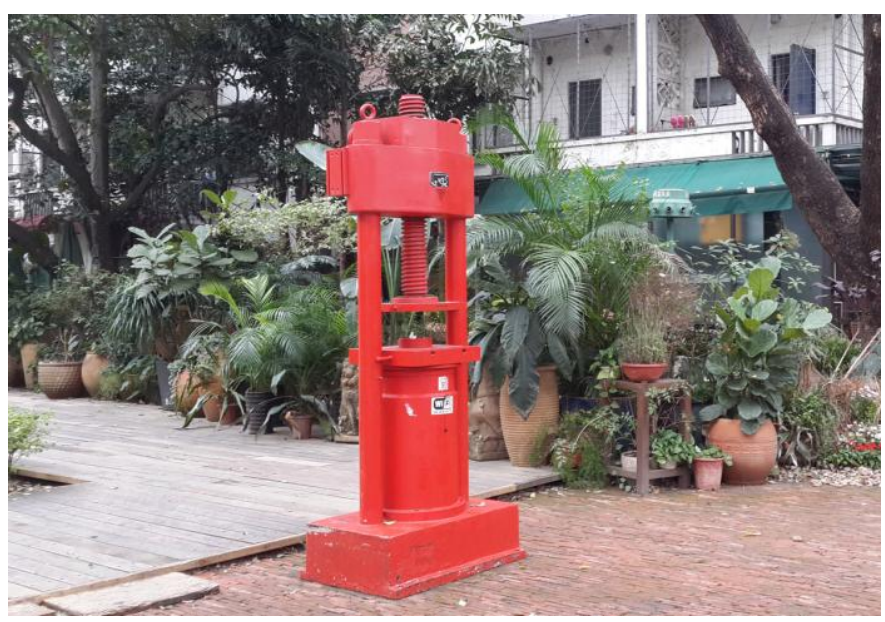

Fig. 3. Landscape Sculpture of Shenzhen OCT LOFT

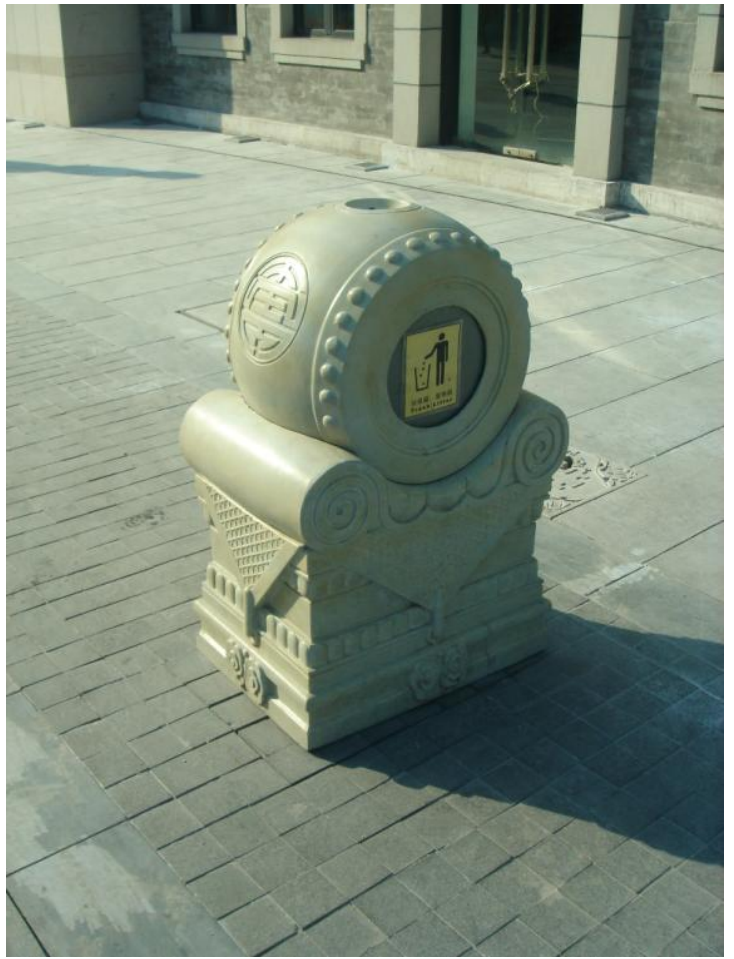

Fig. 4. Public Facilities of Beijing Dashilan 


\section{B. Contextualization of Regional Symbols}

Contextualization is an interactive concept, including two meanings of "emotion" and "environment". The "emotion" in environment refers to people's experience of attitude on whether objective things can meet their requirements. "Environment" is the gather carriers conveyed by semantics, namely the environment for people to live and work. It shall meet real needs people of different culture and different age groups. Any environment symbol can convey the right semantic information in specific situational atmosphere. Therefore, the contextualization of regional symbols is to avoid the isolations of symbols, let symbols, environment and audiences form integral relationship, thus it can resonate emotional scenes. To be specific, firstly, build regional situational context, make regional symbols introduced correspond to other symbols in the scene. The audiences are easier to accept and interpret information conveyed by regional symbols in the environment. As shown in "Fig. 5", the rail preserved that surrounds Guangzhou Red Brick Factory is reformed to themed restaurant of train. Regional symbols such as carriage, track and platform form creative space of contextualization together; secondly, unify regional symbols and emotions of audiences, give full consideration to symbol environment, get familiar with their functional requirements and aesthetic needs for environment of Cultural and Creative Park, and build symbolic forms that can make the communication of semantics go smoothly according to cognitive structure of audiences. As shown in "Fig. 6", in order to build traditional cultural scene, the National Center for Traditional Arts in Yilan County of Taiwan widely apply craft decoration of the famous Koji Pottery in Taiwan to the external walls of the store to form unique regional decorative effect.

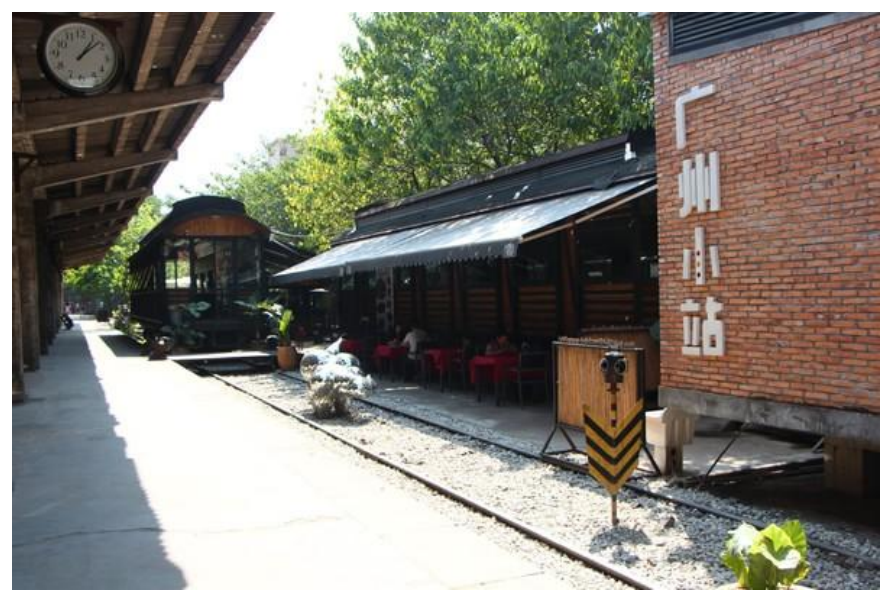

Fig. 5. Train Restaurant of Guangzhou Redtory

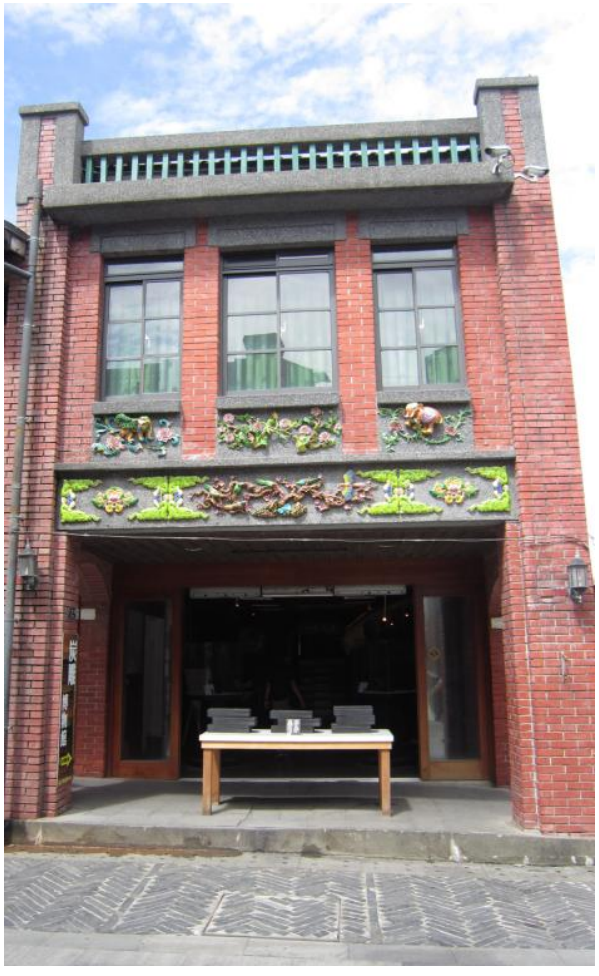

Fig. 6. Building Decoration of Yilan Traditional Arts Center

\section{Landscape Symbol Combination form}

Regional symbols in the environment appear in the form of single image or use the way of group combination to integrate in landscape environment. The regional symbols of group combination shall not only consider coordinated relations between symbols, but also use the rule of formal beauty of modern landscape to form new visual effect of environment. With continuous improvement of people's living standard and aesthetic taste, designers shall attach importance to artistry of environment composition. The rule of formal beauty in traditional constructive art is bound to play an important role. It is our ultimate goal to comprehensively use aesthetic principle, find and create regional landscape language by using creative thinking mode. In specific application, we can confirm the regional symbols after simplification of general situation as basic form, regard it as basic elements such as dot, line, face in composition, then use rules such as variety in unity, rhythm and rhyme as well as contrast and harmony, base on specific site conditions to build diversified landscape effect, such as the white column array and dock in Qijiang Park in Zhongshan City of Guangdong, use modern design methods such as rhythm and rhyme to carry out aesthetic treatment for them to form the contrast of the new and the old, the interweaving of history and reality. Besides, the Hupo Water Tower in the park uses the method of contrast and harmony to cover it in a glass case created by modern science and technology. In addition, with the function of lights, regional symbols generate extraordinary landscape significance. 


\section{CONCLUSION}

The 21st century is the era of creative economy as well as the era when cultural inheritance receives the most attentions. The application of regional symbol will provide spiritual motivation and cultural support, produce huge social benefit and economic benefit and have great significance on inheritance and development of excellent regional culture. The core value orientation of environment of Cultural and Creative Park lies in fashion and creation of space. It decides that regional symbol must break through traditional historical images. Only through insisting on inheriting regional culture in innovation of symbol can keep balance in protecting remains of old industry, historic culture and fashion innovation and meet various requirements of contemporary people for environment of Cultural and Creative Park. Besides, the rich connotation of regional culture also requires the innovation of symbol shall pay attention to innovation of symbols of tangible culture as well as intangible culture. The sources of symbol shall expand to every level of regional culture and organically integrate into various elements of environment of Cultural and Creative Park, in order to open up new thoughts for design and creation of environment of Cultural and Creative Park in the new period.

\section{REFERENCES}

[1] Bai Yuxiao. Analysis on Connotation of Regional Culture and Criteria of Division [J].JiangSu Social Sciences,2011(1):76-80.

[2] Zhang Fengqi. Analysis on Concept and Research Approaches of Regional Culture.[J].Zhejiang Social Sciences,2008(4):63-66.

[3] Liu Shengli. Architecture and Environment in Symbol Meanings.[J].Decoration,2002(12):65.

[4] Zhang Xianrong. Design of Semiotics.[M].Beijing, Chemical Industry Press.2004:127. 